ANNALS JOURNAL CLUB

\title{
App-Based Treatment of Urinary Incontinence: Is the Time Now?
}

Michael E. Johansen, MD, MS, Associate Editor; Christal M. Clemens

Ann Fam Med 2021;19(2):iii. https://doi.org/10.1370/afm.2683.

$\mathrm{T}$ he Annals of Family Medicine encourages readers to develop a learning community to improve health care and health through enhanced primary care. Participate by conducting a journal club. We encourage diverse participants to think critically about important issues affecting primary care and act on those discussions. ${ }^{1}$

\section{HOW IT WORKS}

In each issue, the Annals selects an article and provides discussion tips and questions. Post a summary of your conversation in our online discussion. (Open the article, click on the e-Letters tab, and submit a comment.) Discussion questions and information are online at: https://www.AnnFamMed.org/content/AJC.

\section{CURRENT SELECTION}

Loohuis AMM, Wessels NJ, Dekker JH, et al. App-based treatment in primary care for urinary incontinence: a pragmatic, randomized controlled trial. Ann Fam Med. 2021;19(2):102-109.

\section{Discussion Tips}

Urinary incontinence is a common and, likely, under-diagnosed condition in primary care. Treatment options in primary care include physical therapy, pessaries, and/or medications depending on the type of urinary incontinence. Most of these treatment options have small-to-moderate effect sizes. Further and more convenient treatment options would be welcome in clinical practice.

\section{Discussion Questions}

What question is asked by this study and why does it matter?

- How does this study advance beyond previous research and clinical practice on this topic?

- What effect size would you expect from the app-based intervention?
- How strong is the study design for answering the question? o What is a noninferiority trial?

- What are the benefits and weaknesses of noninferiority trials (compared to traditional superiority trials)?

o What is the concern if a noninferiority trial is underpowered to show inferiority?

o How does the intention-to-treat analysis differ from the per-protocol analysis? How is this different than in superiority trials?

- To what degree can the findings be accounted for by:

o How patients were selected, excluded, or lost to follow-up?

o How the main outcome variables were measured?

o How adherence to treatment in the intervention group was measured?

o What treatments did usual care group receive?

o Chance?

- What are the main study findings?

- How comparable is the study sample to similar patients in your practice? What is your judgment about the transportability of the findings?

- What contextual factors are important for interpreting the findings?

o How would you gauge the potential benefits and harms of the intervention?

- How might this study change your practice? Education? Research?

- Who the constituencies are for the findings, and how they might be engaged in interpreting or using the findings?

- What are the next steps in interpreting or applying the findings?

- What researchable questions remain?

\section{References}

1. Stange KC, Miller WL, McLellan LA, et al. Annals Journal Club: It's time to get RADICAL. Ann Fam Med. 2006;4(3):196-197. https:// AnnFamMed.org/cgi/content/full/4/3/196. 